$$
\text { "ruthven" — 2008/4/9 — 12:24 — page } 419 \text { — \#1 }
$$

\title{
Herschel's heritage and today's technology integration: a postulated parallel
}

\author{
Kenneth Ruthven
}

Abstract. During the early $20^{\text {th }}$ century, advocacy of a range of mathematical technologies played a central part in movements for the reform of mathematical education which emphasised 'practical mathematics' and the 'mathematical laboratory'. However, as these movements faltered, few of the associated technologies were able to gain and maintain a place in school mathematics. One conspicuous exception was a technology, originally championed by the mathematician Herschel, which successfully permeated the school mathematics curriculum because of its:

- Disciplinary congruence with influential contemporary trends in mathematics.

- External currency in wider mathematical practice beyond the school.

- Adoptive facility of incorporation in classroom practice and curricular activity.

- Educational advantage of perceived benefits outweighing costs and concerns.

An analogous perspective is applied to the situation of new technologies in school mathematics in the early $21^{\text {st }}$ century. At a general level, the cases of calculators and computers are contrasted. At a more specific level, the educational prospects of CAS and DGS are assessed.

Key words and phrases: technology integration, mathematics education, historical analysis, mathematical laboratory, squared paper, computer algebra, dynamic geometry.

ZDM Subject Classification: A00, B00, R00, U70.

Copyright (c) 2007 by University of Debrecen 


$$
\text { "ruthven" — 2008/4/9 — 12:24 — page } 420 \text { — \#2 }
$$

\section{New technologies and school mathematics in the early $20^{\text {th }}$ century}

\subsection{Herschel's heritage}

In 1833, a scientific paper by the astronomer-mathematician Herschel recommended a new technology to his fellow researchers. It is clear that he expected this technology to be unfamiliar to his readers, since he described both its design and manner of use with care. Herschel enthused that the technology in question was "so very useful for a great variety of purposes that every person engaged in. . physico-mathematical inquiries of any description, will find [it valuable to have] always at hand" [1, p. 178]. As interest in this new technology grew amongst scientists and engineers, many manufacturers entered the market. Over the second half of the $19^{\text {th }}$ century its price fell by two orders of magnitude and its uptake and use increased enormously.

By the early $20^{\text {th }}$ century, enthusiasm for this technology had spread to education. Reformers saw it not just as a useful tool, but, to quote a prominent English mathematics educator of the time, "as quite the most valuable instrument in our possession for awakening interest" [2, p. 289]. It had become associated with broader educational movements which laid emphasis on giving pupils of all ages 'practical' experience and encouraging their 'self-activity'. The widespread endorsement and adoption of this technology was reported by the newly founded International Commission on Mathematical Instruction (ICMI): "of the value of squared millimetre paper there is no question anywhere" [3, p. 614]. Equally, the English Board of Education suggested that "squared paper was to be found in any well-equipped elementary school" [4]. Clearly, in the early years of the $20^{\text {th }}$ century, there was a squared paper bandwaggon rolling in mathematics education.

But how best to use squared paper appears to have been a matter of some uncertainty. The ICMI report suggested that "its use has been abused by the overextensive treatment of equations and by its application to proving the obvious" [3, p. 614]. Likewise, the English Board of Education issued clarificatory circulars to schools which cautioned, for example, that: "The use of paper ruled in squares for the working of arithmetic examples has no real educational advantages", and sought to rein in the proliferating interpretations of the new slogan of 'graphic(al) algebra'. The Board even offered guidance on avoiding health risks from the new technology: "Any risk of injury to eyesight by the excessive use of squared paper should be avoided"; but gave reassurance that "little danger to health is likely if no paper with rulings less than one-tenth of an inch apart is used" [4]. 


$$
\text { "ruthven" — 2008/4/9 — 12:24 — page } 421 \text { — \#3 }
$$

\subsection{Reform movements}

At the $5^{\text {th }}$ International Congress of Mathematicians in 1912, the Section on Didactics held a session on 'Intuition and experiment in mathematical teaching' which received and discussed an ICMI report surveying those contemporary developments which aimed to provide an 'intuitive', 'perceptual', 'experiential' and 'experimental' base for the subject through "applying mathematics seriously to the problems of life, and... visualizing the work" [3, p. 615]. As already noted, this report acknowledged the rapid uptake and wide-ranging use of squared paper in general, and graphical methods in particular: "Graphic methods of one form or another are now found in the courses in mathematics... in all countries, having gradually made their way from engineering, through thermodynamics and general physics, to pure mathematics" [3, p. 622].

Other key enthusiasms within these developments were geometrical drawing, practical measurement and numerical computation. Geometrical drawing was often linked to material traditionally taught in art or craft classes or in technical subjects; activities such as practical surveying were seen as means of bringing measurement, estimation and computation to life. A key idea was that a more formal treatment of mathematical properties should be built on the experiential base gained from direct use of mathematical instruments and practical understanding of their functionality.

In the United States, the 'laboratory method' advanced by Moore, president of the American Mathematical Society, envisaged that teachers would work with students individually or in small cooperative groups, "to develop on the part of every student the true spirit of research, and an appreciation, practical as well as theoretic, of the fundamental methods of science" [5]. Writing in the American School Review in 1903, Moore's Chicago colleague, Myers, listed the components of "a fairly complete equipment for a mathematical laboratory": as well as "drawing instruments" and "cross-ruled paper", the list included tape measures, weighing scales, surveying equipment, barometers and thermometers, pendulums and gyroscopes, cords and pulleys, and "spherical blackboards, both concave and convex" [6, pp. 737-738].

Godfrey's account of parallel trends in England suggests that there too practical measurement, estimation and computation were closely linked to the introduction of specially-equipped 'mathematical laboratories' [7, p. 453]. However, writing in 1915, in the English Mathematical Gazette, Fawdry noted that the form of 'practical mathematics' generally taking root in schools was actually much more modest than envisaged by its advocates, focusing on topics such as 


$$
\text { "ruthven" — 2008/4/9 — 12:24 — page } 422 \text { — \#4 }
$$

"numerical evaluation of algebraic expressions, accurate construction of geometrical problems, plotting of curves, graphical solutions, [and] use of logarithms in computation", which could "be conducted in a class-room without the use of further apparatus than a box of instruments, some squared paper, and a table of logarithms" [8, p. 36].

\subsection{Adoptive influences}

The differential adoption of technologies associated with these movements reflected considerations of financial and educational cost, as the Subcommission's report noted in relation to slide rules: not just "the expense of the instrument, the cheaper ones not being accurate enough to be of value", but also "the question of time to acquire the necessary facility", with the result that "in the upper classes the numerical computation is performed almost exclusively by the aid of logarithms" [3, p. 624]. More fundamentally, however, stronger versions of the 'practical mathematics' movement - and the idea of the 'mathematical laboratory' in particular - proved poorly matched to shifting educational priorities.

In relation to the United States, Roberts points out how a reform emphasis on 'correlating' the study of mathematics and science ran counter to changes in the composition of the school population: "At the very time that Moore was proposing to justify mathematics education primarily as an aid to science and engineering, the population of high school students was exploding with students, most of whom were not aiming to become scientists or engineers" [5, p. 695]. Moreover: "In the face of the surge of students into the schools, calls for educational efficiency that had emerged during the last half of the nineteenth century became much more insistent and attractive. The efficiency advocates claimed to offer means to control the flood of students by carefully circumscribing requirements in terms of time and effort. In contrast Moore's 'mathematical laboratory', which called for such extravagances as performing all demonstrations in two different ways and for blurring of subject-matter boundaries, could well be seen as a prescription for waste and confusion." [5, p. 694]

In relation to England, Brock and Price argue that the adoption of squared paper was part of a much wider transformation of mathematical education in response to the influence of new educational philosophies and pressure to strengthen scientific and technical education. But why was it that squared paper prospered while so many other technologies faded away? Certainly Fawdry's observation about ease of incorporation into classroom use must be part of the story. But as well as these drivers external to mathematics itself, I would point to the important 


$$
\text { "ruthven" — 2008/4/9 — 12:24 — page } 423 \text { — \#5 }
$$

internal motor of Klein's advocacy of 'functional thinking' as a core mathematical process, integrating pure and applied mathematics, fusing arithmetic with geometry, and emphasising graphical representation [9].

In sum, then, I suggest that the particular success of squared paper and graphical methods depended on the following features:

- Disciplinary congruence through alignment with an influential contemporary trend in mathematics.

- External currency thanks to the growing use of graphing in mathematical practice beyond the school.

- Adoptive facility in terms of relative ease of incorporation in classroom practice and curricular activity.

- Educational advantage in terms of the perceived benefits of use considerably outweighing any costs and concerns.

\section{New technologies and school mathematics in the early $21^{\text {st }}$ century}

The present parallels to this past episode are intriguing. The commercialisation and diffusion of paper-based technologies - such as graph paper and mathematical tables - during the $19^{\text {th }}$ century for use within scientific and technical professions certainly prefigures a similar rise of computer-based technologies in the $20^{\text {th }}$. Even more striking is the educational appropriation of both waves of new technology to reform aspirations for more authentic engagement of students in mathematical activity and enquiry. Looking back a hundred years from now, what stories will our successors tell about the rise of computer-based technologies and their eventual influence on mathematics education?

\subsection{Marginal uptake}

Evidence from the most recent TIMSS study [10] provides a simple indicator of the degree to which use of such technologies has become a regular part of mainstream practice in today's schools. This study operationalises 'regular' use as use by a class in about half of lessons or more. Focusing on the 24 educational systems for which information is available relating to both Grade 4 and Grade 8 provides a good basis for comparison between primary and secondary levels of schooling. First calculators. Across these educational systems, regular calculator 


$$
\text { "ruthven" — 2008/4/9 — 12:24 — page } 424 \text { — \#6 }
$$

use is extremely rare at primary level - reported in only $8 \%$ of classes in the system at the upper quartile of the distribution of systems- and very variable at secondary level - reported in $12 \%$ of classes in the system at the lower quartile against $67 \%$ of classes in the system at the upper quartile. Next computers. Regular computer use in lessons is rare at both levels, reported in $7 \%$ of classes in the system at the upper quartile of the primary distribution, and in only $3 \%$ of classes in the system at the upper quartile of the secondary distribution. Even focusing only on those systems where the majority of classes report having access to computers, regular use is still rare: found in only $10 \%$ of classes at primary level and $4 \%$ at secondary level in the systems at the upper quartiles of the respective distributions.

Such evidence suggests that computer-based technologies in contemporary mathematics education are, in the large, following the wider trend over the last century towards limited uptake and influence of new information and communication technologies within schooling. Reviewing the educational reception of wave upon wave of such technologies, Cuban $[11,12]$ suggests that a recurrent pattern of response can be found: a cycle in which initial exhilaration then scientific credibility give way to practical disappointment and eventual recrimination. He reports that while new technologies have broadened teachers' instructional repertoires to a degree, they remain relatively marginal to classroom practice, and are rarely used for more than a fraction of the school week.

For scholars of school reform, this cautious reception of new technologies forms part of a much wider pattern of largely unsuccessful attempts to change structures of curriculum, pedagogy and assessment at the heart of schooling. While an ever richer diversity of materials and tools is becoming available for use in the mathematics classroom, there is a striking gap between the perspectives of reform advocates and classroom teachers [13]. The main concern of practitioners remains one of developing coherent use of a relatively small selection of materials and tools to form an effective resource system. This depends, in turn, on the more fundamental issue of coordinating working environment, resource system, activity format and curriculum script to underpin classroom practice which is viable within the time economy [14].

\subsection{Calculator counterexample}

These TIMSS findings identify the use of calculators as a relative success in terms of uptake, even if a qualified one - prevalent only at secondary level, and only so in some educational systems [15]. In terms of the factors which were 


$$
\text { "ruthven" — 2008/4/9 — 12:24 — page } 425 \text { — \#7 }
$$

suggested as contributing to the earlier success of squared paper, the situation of calculators is rather less clear-cut. While, with the development of computational technologies, numerical methods have become more significant within mathematically-based professions, they have not become associated with a central disciplinary idea on the lines of Klein's 'functional thinking'. Although, in the earlier days of computer-based technologies within mathematics, 'algorithmic thinking' was proposed as a modern counterpart of 'functional thinking' [16], this idea has not had the same degree of influence on the field as a whole, and appears to have largely disappeared from contemporary discussions of school mathematics.

However, numerical calculation by machine clearly has an established external currency in wider mathematical practice within and beyond the school. Use of a calculator - designed as a cheap, portable, personal technology - represents the most ready educational realisation of this, due to its adoptive ease of incorporation into classroom practice and curricular activity [17]. However, at primary level, where the curriculum has traditionally been organised around highly valorised methods of written and mental calculation, the educational advantage of calculator use remains controversial, and appropriate forms of curricular reorganisation are underdeveloped [18]. But at secondary level, although reservations of principle may still be expressed, stronger pragmatic motivations have led to the relatively widespread use of calculators which can be found in some educational systems, where they serve as convenient means of effecting the numerical calculation needed to support students' work on more advanced mathematical topics.

Likewise at secondary level, symbolic and graphic algebra occupy a predominant place in mathematics curricula, with correspondingly high valorisation of the associated pencil-and-paper techniques. These are prominent in the mathematics assessment which acts as an important 'gatekeeper' for access to further and higher educational opportunities. Thus, during those stages of the curriculum where the development of paper-and-pencil techniques of graph construction and symbolic manipulation remain central, a similar reluctance can be found about giving students access to graphic and symbolic calculators. At all stages of the school curriculum, then, calculator use by students tends to be seen primarily as a means of effecting more elementary techniques where students' use of penciland-paper methods would prove cumbersome, unreliable and distracting.
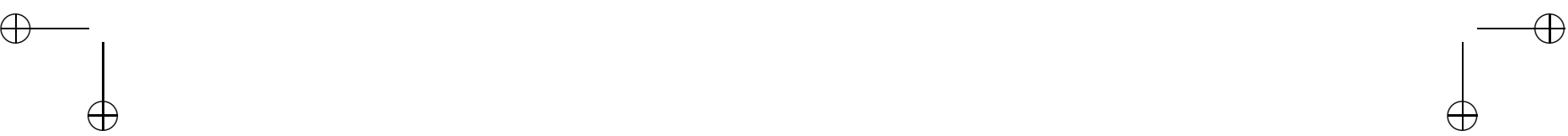


\subsection{CADGME prospects}

What, then, are the prospects for computer algebra and dynamic geometry in secondary school mathematics? While in some respects it is appropriate to discuss these two technologies together, in other respects there are important differences between their cases which deserve to be noted. In particular, while CAS have been developed for use in professional mathematics by correspondingly sophisticated users, DGS have been designed with educational purposes and student users specifically in mind. Thus, while CAS have stronger external currency, DGS have greater adoptive facility. Equally, while the symbolic and graphic algebra to which CAS are applicable occupy a central place in the secondary mathematics curricula of different educational systems and take a broadly similar form, treatments of the 'shape and space' or 'geometry' with which DGS are primarily concerned are much more varied between systems [19]. Thus more uniform judgements of educational advantage can be expected across systems with respect to CAS, whereas with respect to DGS such judgements may vary with the style and emphasis of curricula.

The pioneering development of dynamic geometry systems has taken place largely in countries - notably France and the United States - which have retained a more strongly Euclidean spirit within their school geometry curriculum. However, such an emphasis may lead teachers to perceive DGS as ultimately inimical to the development of proof-oriented reasoning because of the support that they provide for perceptually-based strategies. This has, for example, been reported at upper-secondary level in France [20]. In current practice, then, the perceived educational advantage of DGS is seen primarily as a means of supporting observation and measurement in those (stages of) curricula where more perceptually-based or empirically-grounded forms of reasoning are acceptable. Equally, such activities are often organised in terms of closely guided 'discovery' learning [21]. Indeed, drawing a contrast with the style of DGS use envisaged by pioneering advocates, Hölzl suggests that: "In the literature... the reader is provided with numerous examples of how DGS can support the heuristic phase of problem solving... However, a closer look at various examples [questions whether] the software is used effectively to support a methodical and an active style of knowledge acquisition. Often... [the] DGS is used only in a verifying manner: that is, learners are just supposed to vary geometric configurations and confirm empirically more or less explicitly stated facts." [22]

Likewise, while the content of school-level algebra and calculus may be similar across systems, differences in more fundamental mathematical orientation 


$$
\text { "ruthven" — 2008/4/9 — 12:24 — page } 427 \text { — \#9 }
$$

may shape the ways in which CAS are used and the issues that arise. Here, an interesting contrast has arisen between the approaches of pioneering projects in North America and France: whereas American approaches have emphasised mathematics as a modelling discipline, French approaches have displayed a preoccupation with mathematical anomaly [23]. This helps to explain why complexities of instrumentation have emerged much more strongly in the French work: such phenomena are foregrounded by the use of tasks which deliberately take students beyond their curricular experience and place them in situations devised to expose limitations of the schemes available to them. Indeed, Fey argues that such approaches: "have focused too narrowly on the applications of CAS to traditional algebraic symbol manipulation problems and have looked too hard to find subtle problems that are not well handled by CAS functions... Learning how to use CAS functions to support applied problem solving is not as complicated or as fraught with the potential for mistakes as learning how to use the same tool for more general algebraic reasoning" [24].

Both CAS and DGS make considerably greater demands on the user than do the calculators or courseware currently used more widely by secondary-school teachers and students. This means that the adoptive facility of CAS and DGS as tools for students, even for teachers, is perceived as problematic by practitioners, and this leads to the educational advantage of such forms of use being questioned. Indeed, such perceptions have encouraged the use of CAS and DGS more as a platform for providing teachers and students with prepared templates or applets intended to demonstrate, or support investigation of, a predetermined mathematical idea. This is one important factor shaping the tendency noted above towards a relatively closely led and tightly structured style of classroom use. While this may be effective in providing visual aids to support mathematics teaching and learning, it does not develop students' capacity to use CAS and DGS as tools for mathematical thinking. Nevertheless, the more regular and sustained the attention a curriculum gives to the associated areas of mathematics, the more likely that the return from investing in students' learning to use an appropriate computational tool will be viewed as worthwhile. For example, the prevalence in the United States of whole-year courses focused on Algebra, Geometry or Calculus creates relatively favourable conditions for making such investment. More fundamentally, however, these issues of adoptive facility reflect an educational culture in which mathematical knowledge continues to be construed primarily in terms of forms mediated by the use of pencil-and-paper; from such a perspective,
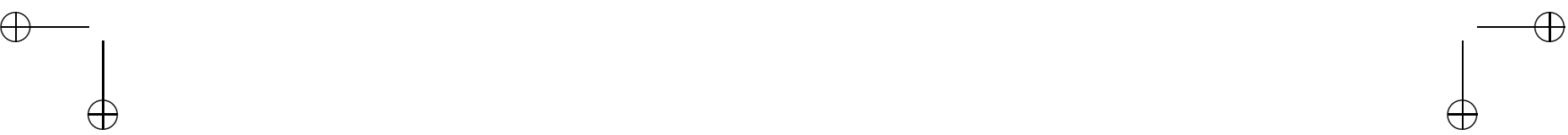


$$
\text { "ruthven" — 2008/4/9 — 12:24 — page 428 — \#10 }
$$

computer-mediated forms of knowledge appear to make only an ancillary contribution. This leads to the potential function of computer algebra and dynamic geometry being seen initially as one of supporting development of mathematical knowledge and understanding as expressed in a pencil-and-paper environment, and subsequently as one of effecting the associated techniques in circumstances where use of pencil-and-paper methods would prove cumbersome, unreliable and distracting. Such tendencies have been noted in studies both of computer algebra [25] and dynamic geometry [21, 26].

Realistically, then, a stronger and wider integration of computer algebra and dynamic geometry into secondary-school mathematics curricula is unlikely to come about until they have come to be accepted as pervasive mathematical tools. This will depend on a more fundamental realignment of the school curriculum with contemporary trends in professional mathematics to create greater disciplinary congruence: in the case of computer algebra, this might centre on giving greater emphasis to ideas of mathematics as a computational and modelling discipline; in the case of dynamic geometry, on increasing acceptance and systematic development of dynamic methods of visual reasoning; in both cases, on according greater recognition to algorithmic dimensions of mathematics. The work being presented at this first CADGME conference promises to provide bases on which such realignment might eventually be built.

\section{Acknowledgements}

This paper has been developed in parallel with one covering the same issues for the ICMI centenary conference [27].

\section{References}

[1] J. F. W. Herschel, On the investigation of the orbits of revolving double stars, Memoirs of Royal Astronomical Society 5 (1833), 171-222, quoted in W. H. Brock \& M. H. Price, Squared Paper in the Nineteenth Century: Instrument of Science and Engineering, and Symbol of Reform in Mathematical Education, Educational Studies in Mathematics, 11 (1980), 365-381 (p. 366).

[2] C. Godfrey, The teaching of mathematics at preparatory schools, School World 4 (1902), 288-291, quoted in W. H. Brock \& M. H. Price, op. cit. (p. 369). 


$$
\text { "ruthven" — 2008/4/9 — 12:24 — page 429 — \#11 }
$$

[3] D. E. Smith, Intuition and experiment in mathematical teaching in the secondary schools, Proceedings of the Fifth International Congress of Mathematicians, vol. II (1912), 611-632.

[4] Board of Education, Suggestions for the Teaching of Arithmetic (1912), quoted in W. H. Brock \& M. H. Price, op. cit. (p. 366).

[5] D. L. Roberts, E. H. Moore's Early Twentieth-Century Program for Reform in Mathematics Education, The American Mathematical Monthly 108 (2001), 689-696.

[6] G. W. Myers, The Laboratory Method in the Secondary School, The School Review 11 (1903), 727-741.

[7] C. Godfrey, The teaching of mathematics in English public schools for boys, Proceedings of the Fourth International Congress of Mathematicians, vol. III (1909), 449-464.

[8] R. C. Fawdry, Laboratory work in connection with mathematics, The Mathematical Gazette 8 (1915), 36-39.

[9] F. Klein, Elementary Mathematics from an Advanced Standpoint, English translation, Dover, New York, undated.

[10] I. Mullis et al., TIMSS 2003 International Mathematics Report, TIMSS \& PIRLS International Study Center, Boston College, 2004.

[11] L. Cuban, Teachers and Machines: The Classroom Use of Technology since 1920, Teachers College Press, New York, 1986.

[12] L. Cuban, H. Kirkpatrick \& C. Peck, High access and low use of technologies in high school classrooms: Explaining an apparent paradox, American Educational Research Journal 38 (2001), 813-834.

[13] K. Ruthven \& S. Hennessy, A practitioner model of the use of computer-based tools and resources to support mathematics teaching and learning, Educational Studies in Mathematics 49 (2002), 47-88.

[14] K. Ruthven, Teachers, technologies and the structures of schooling, Proceedings of the Fifth Congress of the European Society for Research in Mathematics Education [CERME] (to appear).

[15] K. Ruthven, Les représentations des praticiens de l'usage des technologies dans l'enseignement des mathématiques à l'école secondaire en Angleterre, Actes du séminaire national de didactique des mathématiques, Année 2006, Association pour la Recherche en Didactique des Mathématiques [ADRM]/Institut de Recherche pour l'Enseignement des Mathématiques [IREM-Paris 7] (2007), 313-335.

[16] A. Engel, Elementary Mathematics from an Algorithmic Standpoint, Keele Mathematics Education Publications, 1984, English edition of Elementarmathematik vom algorithmischen Standpunkt, Klett, Stuttgart, 1977.

[17] K. Ruthven, Calculators in the mathematics curriculum: The scope of personal computational technology, in: International Handbook of Mathematics Education, (A. Bishop, K. Clements, C. Keitel, J. Kilpatrick \& C. Laborde, eds.), Kluwer, Dordrecht, 1996, 435-468. 


$$
\text { "ruthven" — 2008/4/9 — 12:24 — page } 430 \text { — \#12 }
$$

430 K. Ruthven : Herschel's heritage and today's technology integration: a postulated parallel

[18] K. Ruthven, Constructing a calculator-aware number curriculum: the challenges of systematic design and systemic reform, Proceedings of the $23^{\text {rd }}$ Annual Conference of the International Group for the Psychology of Mathematics Education, vol. 1 (1999), 56-71.

[19] C. Hoyles, D. Foxman \& D. Küchemann, A comparative study of geometry curricula, Institute of Education, London, 2001.

[20] N. C.-Dedeoglu \& E. Erdogan, La place des TICE dans les mémoires professionnels d'IUFM, in: Actes en ligne: Intégration des Technologies dans l'Enseignement des Mathématiques, 2003.

[21] K. Ruthven, S. Hennessy \& R. Deaney, Constructions of dynamic geometry: A study of the interpretative flexibility of educational software in classroom practice, Computers and Education (online 2007).

[22] R. Hölzl, Using dynamic geometry software to add contrast to geometric situations - a case study, International Journal of Computers for Mathematical Learning 6 (2001), 63-86.

[23] K. Ruthven, Instrumenting mathematical activity: Reflections on key studies of the educational use of computer algebra systems, International Journal of Computers for Mathematical Learning 7 (2002), 275-291.

[24] J. Fey, Connecting Technology and School Mathematics: A Review of The Didactical Challenge of Symbolic Calculators: Turning a Computational Device into a Mathematical Instrument, Journal for Research in Mathematics Education 37 (2006), 348-352.

[25] D. Guin, K. Ruthven \& L. Trouche (eds.), The Didactical Challenge of Symbolic Calculators: Turning a Computational Device into a Mathematical Instrument, Springer, New York, 2005.

[26] C. Laborde, Integration of technology in the design of geometry tasks with CabriGeometry, International Journal of Computers for Mathematical Learning 6 (2001), 283-317.

[27] K. Ruthven, Mathematical technologies as a vehicle for intuition and experiment: a foundational theme of the ICMI, and a continuing preoccupation, paper prepared for the ICMI Centennial Conference, Rome, March 2008.

KENNETH RUTHVEN

UNIVERSITY OF CAMBRIDGE

FACULTY OF EDUCATION

184 HILLS ROAD

CAMBRIDGE CB2 $8 \mathrm{PQ}$

UNITED KINGDOM

E-mail: kr18@cam.ac.uk

(Received October, 2007) 